\title{
Lembranças pessoais, memórias coletivas: As mulheres italianas e a grande emigração para o Brasil $^{*}$
}

\author{
Syrléa Marques Pereira \\ Universidade do Estado do Rio de Janeiro
}

\section{Heranças familiares imateriais}

Habitualmente, quando um de nossos ascendentes vem a falecer, a família reúne os descendentes para realizar a partilha de seus bens. Em meu grupo familiar não foi diferente. No ano de 1986, com a morte de minha avó materna, Stella Consani Marques, coube-me como herança não um imóvel ou outro bem material de valor monetário, mas sim uma pequena caixa de charutos repleta de fotografias, documentos e objetos pessoais.

Tão logo coloquei os olhos na caixinha a reconheci, pois quando era criança e ficava sob os cuidados de Stella, nas tardes que as suas tarefas domésticas escasseavam, eu a via retirar a caixa de um compartimento escondido debaixo da mesa da sala de estar e contemplar os objetos nela depositados.

Observando os artefatos da caixinha, constatei que Stella nela depositou ao longo de sua vida muitos retratos, cartóes-postais, participações de nascimentos, aniversários, batizados e casamentos, santinhos de missa de sétimo dia, entre outros objetos pessoais, que lhe foram enviados por suas tias, irmãs, filhos e sobrinhos. Ou seja, aquele era o lugar especialmente reservado às suas lembranças e à memória da família: vida, morte, viagens, festas etc.

Recebido o legado familiar, prontamente compreendi que deveria zelar pela conservação de seus bens. Então, tal como Stella, tratei de depositar a caixa em um lugar seguro: o fundo de um armário.

Uma década depois, em 1997, levada pela necessidade de apresentar um trabalho de pesquisa em um curso de especialização em história, passei a observar os objetos que compunham a minha herança não mais 
com olhos saudosos e contemplativos, mas sim inquisidores. Não obstante, a condição de historiadora me assegurava que aqueles objetos eram índices de experiências vividas e as fotografias se constituíam em suportes que divulgavam imagens que a família havia selecionado para ser lembrada no futuro. Sendo assim, não era apenas a neta de Stella que a havia substituído na função de guardiã da memória da família que se voltava para os objetos da caixinha, mas também a historiadora. ${ }^{1} \mathrm{Ou}$ seja, os objetos e as fotografias eram verdadeiras relíquias da caixinha de lembranças de Stella, pois assim a denominei. ${ }^{2}$

Ao analisar os objetos da caixinha, um santinho de missa de sétimo dia me chamou particularmente a atenção, pois nele havia uma fotografia de uma mulher, de olhos expressivos e tristes, que me observava tão profundamente como se houvesse algo a revelar. Mas quem era aquela desconhecida? Como resposta a minha pergunta, logo abaixo da imagem estava escrito: Maria Consani Fazzi, nascida em Lucca, na Itália, em 1885 e falecida em Passa Quatro, Minas Gerais, em 1946.

Havia identificado o primeiro vestígio de uma migração de peninsulares para o Brasil apontado pela caixinha de minha avó. A partir desse instante, encontrei e segui vários outros sinais, bem como passei a investigar quando, como e quais pessoas haviam participado dessa experiência migratória. Um trabalho de reconhecimento das pessoas que há mais de um século foram fotografadas e "viviam" na caixinha, começando por Maria Consani Fazzi. Logo descobri que seu nome de solteira era Maria Annunziata Consani. Ela era a irmã mais velha de Giuseppe Consani, pai de Stella. Investigando um pouco mais identifiquei os pais de Maria e Giuseppe: Teodora Pellegrini e Giovanni Consani.

Farejando as pistas e seguindo os rastros que a caixinha me apontava, descobri que duas filhas de Giuseppe estavam vivas: Célia Consani, com 78 anos, e Laís Consani Scarpa, então com 89 anos. Localizei ambas as mulheres, mostrei-lhes a minha caixinha de lembranças, elas identificaram outras pessoas retratadas, narraram muitas histórias protagonizadas pelos parentes italianos antes mesmo da partida da Península Itálica e após a chegada ao Brasil, em meados dos anos 1870. Logo descobri que o grupo imigrante se fixou na então freguesia de $\mathrm{N}^{\mathrm{a}}$. $\mathrm{S}^{\mathrm{a}}$. do Amparo, que pertencia ao município de Barra Mansa, no estado do Rio de Janeiro.

Localizei e entrevistei, posteriormente, mais sete mulheres descendentes dos Pellegrini-Consani e, assim, constituí uma rede de informantes orais unidas por laços de parentesco, direto ou indireto, que foram capazes de 
apontar, ao longo de nossas conversas, a irmã que tinha muitos casos para contar, a prima que se lembrava de muitas histórias, ou a tia que certamente não se recusaria a narrar alguns eventos. ${ }^{3}$ Isso porque as depoentes são pessoas referenciais para seus grupos quando o assunto é lembrar o passado comum e narrar histórias familiares. Ao desempenharem tais atividades, essas mulheres igualmente podem ser tratadas como guardiãs da memória familiar. ${ }^{4}$

No entanto, não havia qualquer informação sobre a localidade exata de onde os imigrantes haviam partido do outro lado do Atlântico. Aliás, o local estaria eternamente perdido no território italiano, se Laís Consani, durante um de seus depoimentos, não pronunciasse a palavra "Oneta". Havia lembrado o nome da aldeia que a família deixou para trás. Não fosse seu trabalho de memória, eu estaria até hoje de arquivo em arquivo em busca dos aldeões, pois os documentos oficiais italianos freqüentemente registravam como localidades de partida os municípios, não chegando a apontar a aldeia ou o povoado. ${ }^{5}$

Identificado o local de saída dos imigrantes, o passo seguinte foi conhecer os atuais habitantes de Oneta, localizar entre eles descendentes no desempenho do papel de guardiōes da memória familiar, entrevistá-los e, concomitantemente, realizar o trabalho de levantamento de fontes. $\mathrm{O}$ que veio a ocorrer, pois entre os meses de setembro a novembro de 2006 residi em Oneta e conversei com seis mulheres e seis homens cujos antepassados foram imigrantes no Brasil e também nos Estados Unidos. Entre essas pessoas identifiquei cinco guardiōes da memória familiar Maria Grazia Micheli, Maria Grazia Gigli, Maurizio e Vincenzo Micheli, e Ferruccio Silvestri. Todos eles, exceto o último que conserva suas fotografias em um álbum, são proprietários de caixinhas de lembranças. ${ }^{6}$

Deste modo, foram atadas as duas localidades que vivenciaram a mesma experiência, dois mundos foram reaproximados depois de decorrido mais de um século e, durante esse encontro, outras caixinhas de lembranças vieram à tona, olhares e lembranças puderam ser trocados, perguntas ganharam respostas.

O mais importante, porém, foi que, reconhecendo a invisibilidade das mulheres nos estudos que tratam dos grandes fluxos migratórios transnacionais e objetivando dar-lhes voz, o lembrar e contar casos e histórias que reconstroem a experiência de deslocamento foi prerrogativa que se concentrou nas mulheres. Somente dessa maneira as mulheres ganharam e um rosto, um nome, uma identidade, como também foram 
reconhecidas nos diversos papéis sociais que desempenharam. Muitas mulheres permaneceram em suas aldeias de origem e, devido ao êxodo masculino, viram suas vidas, as relaçôes de poder em seus núcleos familiares e na própria comunidade significativamente transformadas, ou seja, influenciadas pelo fenômeno migratório. ${ }^{7}$

É bem verdade que muitos foram os avanços nesse campo de investigação, mas ainda hoje encontramos diversos e graves problemas. "Além das dificuldades documentais, bibliográficas e arquivísticas das fontes em geral 'deformadas' ou 'carentes', se agrega o sexocentrismo vigente até há pouco tempo na história e nas disciplinas sociais", conforme observou Luisa Passerini. ${ }^{8}$

Considerando tais implicações e premissas, as mulheres são aqui vistas como protagonistas ativas, capazes de várias ações, de organizar estratégias, fazer escolhas e tomar decisões, e não como participantes silenciosas ou trabalhadoras invisíveis. Consequentemente, a escolha por narrar a história no gênero feminino muda o "fazer" história. Assim, surge um sujeito coletivo, o tempo ganha novos marcos, a vida é percebida sob outro ponto de vista, as açōes e decisōes ocorrem a partir de questôes muito próprias às mulheres. Em suma, são processos sempre muito diferentes daqueles vivenciados pelos homens. 9

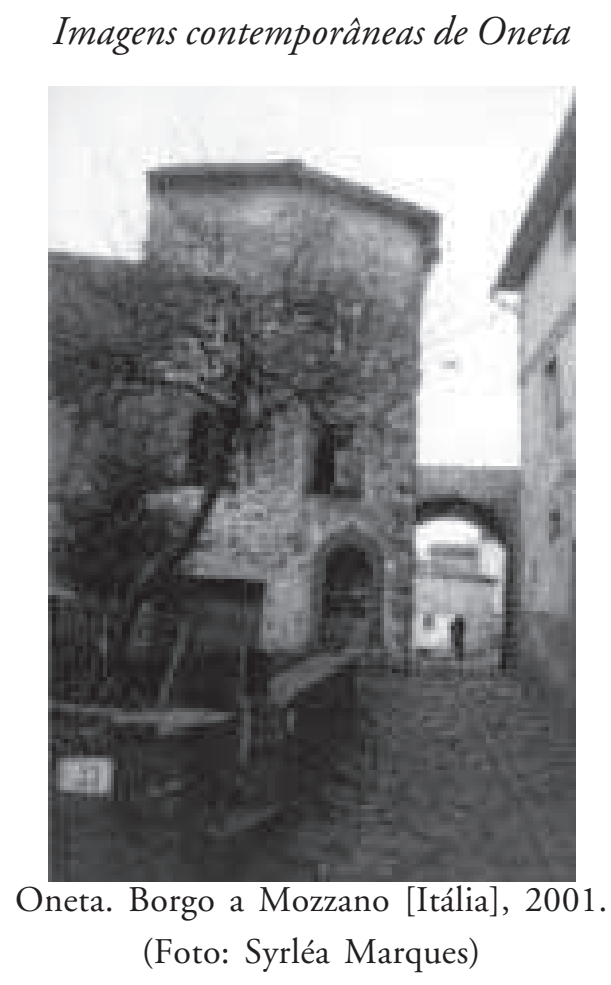

Maracanan $n^{\circ} 6$ 
A primeira vez que cheguei a Oneta fui tomada por um sentimento de enorme satisfação, porque esse lugar representa a concretude espacial de minhas origens, a terra de meus ancestrais; mas no mesmo instante vivenciei um déjà-vu. Apesar de não haver lá pisado anteriormente, tudo me pareceu muito familiar: o lavatório comum que no passado era utilizado pelos moradores, o pórtico de entrada, a igreja milenar e seu campanário. Tal familiaridade foi possível graças às recordaçōes e histórias que me foram narradas pela depoente oral Laís Consani Scarpa. Desde bem pequena, Laís se tornou a ouvinte de muitas histórias de sua avó Teodora Pellegrini. Histórias que me colocaram em contato com mulheres e homens de uma Oneta de fins do Oitocentos, seus desejos e temores diante da vida; apresentaram-me seus homens trabalhadores que buscavam empregos nas cidades vizinhas e suas mulheres com as quais "condividi" não só o nascimento de seus filhos, como também a dupla jornada que lhes cabia: as tarefas domésticas e o cuidado com os filhos, além do cultivo da terra e produção de bens, visto que seus maridos sempre permaneciam distantes.

Contudo, qualquer visitante que hoje chegue a Oneta, percebe que ela encontra-se literalmente incrustada em uma das montanhas que conformam os Apeninos Toscanos. Foi construída seguindo o desenho da montanha, aproveitando oportunidades um pouco mais planas ou mesmo nivelando terrenos, o que possibilitou erguer suas edificaçóes e o cultivo da terra. Em sua paisagem predominam bosques densos de castanheiras e de carvalhos, faias, nogueiras e amieiros. Esta última espécie, serviu de inspiração para o nome do povoado: em latim Alnus, por derivação, Alneta, em italiano Ontano e, por fim, chegou-se a Oneta. ${ }^{10}$ Não faltam também antigas macieiras, pereiras e figueiras que, regularmente, dão seus frutos.

No povoado, os sinais de permanência e imobilidade parecem evidentes. Tem-se a nítida impressão que, ali, o tempo se negou a fluir. Ultrapassandose o pórtico que dá acesso ao interior de Oneta, está o antigo conjunto de poucas dezenas de casas, interligadas por antigas e estreitas ruelas circulares, tendo, bem ao centro, a igreja dedicada a Santo Ilário. Todas essas construçōes foram erguidas em pedra e exibem marcas arquitetônicas etruscas e romanas. Porém tal sensação é falsa. Um olhar mais minucioso revela que a aldeia se transformou: as terras a seu redor não são mais cultivadas; as oficinas de seus artesãos e as duas casas de comércio que um dia funcionaram, hoje vivem na memória de seus moradores; e, reparando bem, a tecnologia nela chegou, pois alguns portôes de casas são abertos eletronicamente. 


\section{2}

Conhecendo um pouco de sua história, constata-se que tampouco a aldeia foi avessa a movimentos, ao contrário, seus moradores sempre conheceram outras regiōes e mundos, da própria Península, de nações européias e d'além mar. Não foram poucos os moradores que romperam os limites do povoado para se estabelecer em municípios próximos, como Borgo a Mozzano e Lucca; um pouco mais distantes como Pisa e Livorno; em nações vizinhas à Itália, como França e Bélgica; e em outras bem mais distantes, como o Brasil, os Estados Unidos e, mais recentemente, a Austrália.

Segundo a prefeitura de Borgo a Mozzano, em 2006, sua população residente era composta por 127 habitantes. ${ }^{11}$ No entanto, aproximadamente 52 pessoas realmente vivem em Oneta; os outros indivíduos recenseados conformam uma população flutuante, que permanece na aldeia somente durante os verōes e, por esta razão, a maior parte das casas está sempre fechada boa parte do ano. A maioria de seus moradores possui mais de 65 anos de idade, goza de aposentadoria, e não mais depende do cultivo e exploração da terra e dos frutos fornecidos por seus bosques. Exceção para Maria Luisa Ugoline que, em seus 77 anos, continua residindo e trabalhando as terras de seus antepassados, junto com sua filha e genro. Distantes das atividades de Maria Luisa, as mulheres de Oneta, de forma geral, dedicam-se às tarefas domésticas e, em função de um reduzido número de jovens, a maior parte não mais possui filhos para cuidar e educar, usufruindo da companhia de netos ou sobrinhos. Já os homens, preenchem seus dias cortando madeira nos bosques; cuidando de seus vinhedos, hortas e pomares, além de galinhas e patos. Com a regularidade permitida pela legislação, praticam a caça de pequenos pássaros e outros animais, como o porco-espinho, o cervo e o javali.

Juntos, mulheres e homens, recolhem cogumelos, castanhas e frutos silvestres - como morangos e framboesas. Todos os anos, com a chegada do outono, têm inicio a vendemmia: a colheita de uvas. Nesse momento, grupos familiares se reúnem, colhem suas uvas e passam a produzir o vinho do ano seguinte, sendo que, ainda o fazem de forma bastante artesanal ou, quando muito, utilizam máquinas simples. Já em meados de novembro, tem lugar a colheita de azeitonas e, mais uma vez, algumas pessoas se encontram para a produção do azeite.

No entanto, se hoje essas pessoas desempenham tais atividades desobrigadamente, somente para o consumo próprio e até mesmo como lazer, o fazem porque aprenderam com seus antepassados, que de forma 
sistemática exploravam os recursos da montanha e da terra, extraindo o alimento e os meios que garantiam a própria sobrevivência e a de suas famílias.

Como também foi com seus antecessores, que compreenderam que deixar Oneta para procurar trabalho em outras cidades e países, era uma condição ou mesmo uma alternativa para complementar o orçamento familiar e melhorar a vida.

Mas quem foram seus antepassados e como eram compostos seus núcleos familiares? A quais ofícios e profissóes essas pessoas se dedicaram? Como esteve organizada a economia local, principalmente no tocante ao cotidiano, e em que medida os fluxos migratórios habituais de moradores de Oneta para regióes da Península e para naçóes européias, relacionaramse com o grande êxodo transoceânico? E ainda, como os deslocamentos repercutiram na vida daqueles que permaneceram e na própria estrutura da aldeia?

Para responder a essas perguntas é necessário ir ao encontro dessas pessoas no Oitocentos, pois foi durante esse momento histórico que, para alguns de seus moradores, apresentou-se a possibilidade de deixar Oneta, cruzar o Atlântico e continuar suas vidas no distrito de Nossa Senhora do Amparo, localizado no município de Barra Mansa, no estado do Rio de Janeiro.

\section{Uma Oneta Oitocentista ou A temporada das mulheres}

No final do ano de 1824, o pároco da igreja local, dedicada a Santo Ilário, arrolou 79 núcleos familiares, descendentes de 20 famílias: Andreoli, Barsanti, Brunini, Gambogi, Gamelli, Gigli, Lippi, Lotti, Lucchesi, Mattioli, Pellegrini, Micheli, Puccinelli, Ponzi, Silvestri, Simi, Simonetti, Tomei, Fazzi e Sartini. ${ }^{12}$

Observando a composição dos núcleos familiares, constata-se que predominavam as famílias extensas e patriarcais, aqui consideradas como completas. Elas eram compostas por marido, mulher, filhos não casados, filhos casados e a relativa família, podendo contar com a presença de um agregado: uma adolescente ou uma mulher adulta que desempenhavam atividades domésticas ligadas ao mundo privado; ou um menino destinado às tarefas agrícolas ou artesanais, como um aprendiz, sempre trabalhando com o chefe da família. ${ }^{13}$ Mas havia as famílias extensas incompletas, com a ausência de um dos cônjuges; as famílias nucleares completas, 


\section{Dôssie Imigração}

compostas por marido, mulher e filhos; como também as famílias nucleares incompletas.

Entre essas famílias prevaleceram os vínculos de descendência verticais, nos quais estavam explícitos o espírito de submissão e obediência hierárquica. Os homens, enquanto pais e/ou maridos, proprietários ou não de seus terrenos e habitações, detinham a autoridade familiar, sendo designados para as obrigações e função de chefe de família. Situação que se alterava com a morte do homem que desempenhava a respectiva função, quando era substituído pela sua mulher, viúva. Tal estrutura de poder familiar patriarcal manteve-se com bastante regularidade até os anos 1870, quando o crescimento das migrações masculinas sazonais produziu um rearranjo de forças nos núcleos familiares, como se verá adiante.

No que diz respeito ao número de componentes dos grupos, se observarmos as famílias de Oneta em bases estatísticas, é possível constatar que entre 1818 e 1884, seus núcleos familiares possuíam em média 4,5 membros. No entanto, se a análise levar em consideração as composições familiares reais, isto é, as pessoas que dividiam o mesmo teto, verifica-se que, pouco a pouco, as moradias foram se tornando pequenas para abrigar todos os seus componentes. Em primeiro lugar, porque aumentou o número de componentes das "famílias tradicionais," aquelas nucleares; em segundo lugar, à medida que seus filhos homens formavam novas famílias, passavam a residir na casa de seus pais com a mulher, e não na casa dos pais da mulher, ou seja, as normas que prevaleceram na comunidade foram a patrilocalidade e a virilocalidade. ${ }^{14}$

Quanto às regras definidas pela comunidade para a organização da parentela, entre os grupos familiares de Oneta prevaleceram os casamentos endogâmicos-residenciais, parentais e locais, os quais deram origem a redes de parentela e de solidariedade que garantiam alianças e ajuda mútua em diversos momentos da vida e, sobretudo no trabalho, visto que a unidade produtiva era baseada no trabalho familiar. Muito embora o casamento criasse as famílias, eram também as famílias que utilizavam os matrimônios para estabelecer vínculos entre elas. ${ }^{15} \mathrm{Na}$ referida comunidade, esses laços garantiam a cooperação econômica entre os grupos, visto que, sendo a economia caracteristicamente familiar de subsistência, necessitavam para sua manutenção e reprodução do envolvimento de todos os componentes do núcleo doméstico.

Mas a endogamia também impunha suas regras. Havia uma seletividade para as uniōes, principalmente entre as famílias proprietárias de seu próprio 
pedaço de terra ou de algum bem patrimonial. Dessa maneira, vínculos passavam a ser construídos entre determinados grupos e, obviamente, reforçava-se o patrimônio familiar existente. Sobretudo, regulava-se os matrimônios entre famílias proprietárias e não-proprietárias, ou seja, entre filhos de proprietários e filhos de pequeno-meeiros ou camponeses assalariados.

Em função dos casamentos serem endogâmicos, caracteristicamente parentais e locais, permitindo-se as uniōes entre primos, com o correr do tempo, surgiu um entrelaçado de famílias e, consequentemente, os vínculos entre os grupos familiares se tornavam mais estreitos. Tanto, que a depoente oral Maria Ponzi, moradora de Oneta, logo qua a conheci, afirmou: "Aqui todos são parentes, quando se volta um pouco no tempo, descobre-se um primo."

Além dos vínculos de descendência linear, existiam os laços de colateralidade, ou seja, as ligaçóes de parentela reais ou adquiridas, no sentido horizontal, que ligavam, através de uma fina rede de normas e relações, tanto sociais quanto econômicas, os parentes colaterais. Tais laços contribuíam para a criação e estabilização das relações interfamiliares e, ao contrário das relações parentais verticais, nas de colateralidade prevaleciam a solidariedade, a mutualidade e a reciprocidade, onde significativos eram o sistema de favores e contra-favores que ligavam os vários núcleos familiares, e que não raro, transcendiam às relaçôes sociais pessoais, alcançando o nível do econômico.

Assim, havia uma cooperação entre vizinhos, que podiam também ser parentes, que se concretizava nas trocas de atividades de trabalho desenvolvidas na residência da própria pessoa, como o sacrifício de animais domésticos e o beneficiamento de suas carnes para o consumo familiar; ou a debulha do milho. ${ }^{16} \mathrm{~A}$ ajuda mútua entre os moradores também se fazia sentir nos momentos nos quais alguém adoecia ou necessitava de cuidados especiais, como as mulheres que eram auxiliadas no momento do nascimento de seus filhos. ${ }^{17}$

O que se pode conjecturar é que além das relaçôes de parentela reais que garantiam auxílio aos membros de uma mesma família nos momentos mais duros da vida, também acontecia da solidariedade criar o sentimento de pertencimento a um grupo familiar, de "construir" verdadeiros laços de consanguinidade. Por outro lado, não se pode desconsiderar o fato de que em Oneta a grande maioria dos casamentos ocorreu entre membros de duas dezenas de famílias e, provavelmente, seus moradores se sentiam 
unidos por laços de parentesco. Fossem tais laços reais ou fictícios, o importante é que se desdobravam em atitudes solidárias.

Essas famílias grandes, alargadas, eram muito importantes, tendo em vista que o sistema econômico da aldeia era de subsistência, onde a produção estava baseada na unidade familiar. As atividades eram diferenciadas de acordo com o sexo e também com a idade de cada um de seus membros e, não raro, também recorria-se à cooperação de amigos e vizinhos em algumas tarefas.

A maioria dos camponeses cultivava a terra no sistema de meação, pois em Oneta poucos eram proprietários de seus terrenos. O que significa dizer que, pela ocupação da terra, os camponeses deveriam entregar ao proprietário metade de toda a produção sobre ela, o que era feito em gêneros, em mercadorias e não em espécies. Adriana Dadà se refere a esse sistema que predominou na área apenínica e subapenínica toscana como de "meação pobre". Trata-se de um sistema que não incorporou a mecanização ou novas culturas, em função das características geológicas ou agrárias do solo ou por resistência por parte dos proprietários em empreenderem mudanças na gestão de suas terras e nas relações com os meeiros. Conseqüentemente, a produção era reduzida. ${ }^{18}$

A vida desses camponeses e camponesas era regida pelo nascer e o pôr do Sol; o tempo mais longo, tempo decorrido, era mensurado pelas estações do ano, e nelas, encontravam-se distribuídas as atividades desenvolvidas nos campos e seus desdobramentos no âmbito da casa. Mas esse tempo também era medido pelas ausências de membros dos grupos que se encontravam trabalhando fora da povoação.

Entre os meses de maio-junho até novembro-dezembro, ou seja, durante a primavera, o verão e o outono, todos trabalhavam juntos. Os homens eram empenhados na lavra dos terrenos, na semeadura dos grãos, na poda das plantas e na colheita de frutos, nos trabalhos mais pesados; enquanto as mulheres cuidavam do horto, cortavam o feno e talhavam os grãos, quando era o momento. Além disso, cortavam as ervas para alimentar os animais, além de trabalhar o cânhamo. ${ }^{19}$ Mas toda a família trabalhava nos campos e extraía os frutos dos bosques, inclusive as crianças. $\mathrm{Na}$ realidade, até as primeiras décadas do Novecentos meninos e meninas com 8-10 anos eram considerados em idade de trabalho. A maioria das crianças da região onde se localiza Oneta, de acordo com as estatísticas nacionais, começava muito cedo a desenvolver tarefas ligadas ao pastoreio e à agricultura, durante o período precedente à escolarização, que durava 
dois ou três anos. Conforme observou Adriana Dadà, dramática era a situação dos meninos, jovens adolescentes, que emigravam com um membro mais velho da própria família - o pai ou o irmão mais velho para trabalhar como ajudantes; outras vezes se tornavam aprendizes a serviço de um vendedor ambulante. Durante muitos meses, quando não anos, se afastavam da família e rodavam a Europa e até mesmo a América. Mas para o núcleo familiar, era menos uma boca para matar a fome. ${ }^{20}$

Em virtude da topografia íngreme, aliada à elevada altitude e aos invernos rigorosos, os camponeses cultivavam uvas e olivas, não faltando frutas como maçãs e pêras. Também plantavam milho, trigo, batatas, feijão, algumas verduras e o cânhamo utilizado para a tecelagem. De seus bosques recolhiam castanhas. Com o trigo faziam o pão e a massa - o macarrão; com o milho se preparava a polenta e as focaccine ${ }^{21}$ com a castanha a farinha doce, a polenta de neccio e as neccie. Estas sim, para muitos, constituíram-se no único alimento à mesa, pois era elaborado com farinha de castanhas, água e sal, assadas sobre uma pedra. ${ }^{22}$ Vale ressaltar que o trigo, milho, farinha de castanhas e o cânhamo estiveram entre os principais produtos comercializados nas feiras semanais de Borgo a Mozzano, que ocorria às quartas-feiras, instituídas pelo então Granducato di Toscana, no ano de $1852 .{ }^{23}$ Algumas famílias criavam animais, mas somente para o consumo, como forma de assegurar o leite, o queijo e alguns ovos, não chegando a ser comercializados.

O trabalho agrícola e o extrativismo praticado nos bosques exigiam alguns profissionais especializados, como o operador de moinho, maquinário este indispensável para a produção de farinhas e azeite, os lenhadores e até os carvoeiros. Vale ressaltar que estes últimos ofícios requeriam muita técnica para o corte das árvores e para a fabricação de carvão, como também estavam entre os trabalhos mais duros da montanha, pois os homens e os jovem-ajudantes, permaneciam nos bosques por meses, sempre sujos e impregnados de fumo e odor de carvão. Como eram detentores de técnicas incompreensíveis pelos moradores, não era incomum algumas pessoas os identificarem com forças ocultas, demoníacas, com as quais pareciam que comunicavam. ${ }^{24}$ Mas Oneta também possuiu suas costureiras e um costureiro; um pequeno comerciante; um carroceiro; sapateiros, fiandeiras, marceneiros e alguns figurinai, escultores em gesso. ${ }^{25}$

Entretanto, entre os meses de dezembro-janeiro até maio-junho, isto é, do inverno até o final da primavera, os camponeses e camponesas 
continuavam desempenhado as tarefas diárias que garantiam a sobrevivência do núcleo familiar, porém sem contar com o trabalho de algumas pessoas. É que a economia apoiava-se sobre dois sustentáculos: um era o trabalho dos camponeses, artesãos e demais profissionais que na aldeia residiam permanentemente; e o outro era constituído pelas rendas daqueles que emigravam. Sendo assim, em cada núcleo familiar, com o início do inverno, pelo menos um componente masculino, que podia ser o chefe da família ou o primogênito, e algumas vezes uma mulher, passava pela experiência da emigração. As famílias confiavam a essas pessoas um projeto emigratório com tempo determinado: deveriam trabalhar, reunir algumas economias, com as quais supririam as várias necessidades da parentela que permaneceu na aldeia, retornando após um período préestabelecido.

As rendas que traziam os seus emigrantes possuíam fins previamente definidos: primeiramente eram utilizadas para complementar o orçamento doméstico; em seguida para a compra de um pedaço de terra ou mesmo promover o alargamento da propriedade familiar, por menor que ela fosse; depois se investia na própria atividade, no caso de artesãos, proprietários de moinhos e pequenos comerciantes e, por último, no financiamento da própria emigração. Enfim, emigrava-se para "permanecer", partia-se para trabalhar e retornava-se para consolidar a própria posição econômica em seu local de origem. ${ }^{26}$

De forma geral, nessas áreas onde predominam a paisagem montanhosa, períodos diferentes de maturação dos produtos levaram, por séculos, os camponeses em direção à planície, para desenvolverem atividades agrícolas como o corte do feno, o debulhar dos grãos, os cuidados com o bicho da seda, os trabalhos de aragem de terrenos e a poda de vinhedos. Essa era a condição para muitos profissionais exercitarem o próprio ofício. Assim, em outubro/novembro, após a colheita das castanhas, uvas e azeitonas em suas aldeias, os camponeses partiam para desenvolver idênticas tarefas em outras localidades, retornando aos seus povoados de origem entre maio e junho, quando a necessidade de muitos braços para a agricultura exigia sua volta. Portanto, tais deslocamentos eram sazonais e possuíam uma cadência anual. ${ }^{27}$

As mulheres se incluíram nos fluxos migratórios sazonais e, geralmente, para se empregar como empregadas domésticas, cozinheiras, camareiras ou amas-de-leite. ${ }^{28} \mathrm{~A}$ atividade de doméstica nas grandes e pequenas cidades italianas moveu massas de mulheres do campo entre a pré- 
adolescência e o casamento. Era uma das maneiras através das quais as filhas contribuíam, ao lado dos irmãos, com a renda familiar, além da possibilidade de também constituir por essa via o dote de seus futuros casamentos. $^{29}$

É interessante salientar que os deslocamentos foram pouco a pouco atingindo distâncias cada vez maiores. Na primeira metade do Oitocentos, os trabalhadores e trabalhadoras de Oneta saíam para se empregar em aldeias vizinhas, em municípios na própria Península e em cidades no continente europeu. $\mathrm{Na}$ segunda metade desse século, além das estradas anteriores que continuaram a percorrer periodicamente para trabalhar, habitantes de Oneta passaram a trilhar uma nova, a da América: se para o ano de 1855 há o registro de uma partida para o Novo Continente, entre 1866 e 1880 foram 10 pessoas a deixar Oneta em direção à "América". 30

Como observou Franco Ramella, nos movimentos emigratórios de trabalho em lugares distantes, característicos de áreas de montanhas, a duração da permanência fora dos locais de origem dos indivíduos podia variar de acordo com o tipo de trabalho conseguido, e eram fluxos caracterizados por um modelo específico: eram circulares. A vida de trabalho dos emigrantes era ritmada pelas saídas e retornos periódicos aos lugares de origem, que se interrompiam somente quando decidiam se transferir definitivamente para outra localidade. ${ }^{31}$

Nesse sentido, é possível pensar que, quando na segunda metade do Oitocentos novas oportunidades de trabalho estavam sendo abertas no Novo Continente, geradas pelo desenvolvimento econômico mundial, esses emigrantes souberam agarrar tais oportunidades: lançaram-se na travessia do Atlântico. Provavelmente, a escolha da emigração transoceânica não representou a única opção para as pessoas de Oneta e para os peninsulares naquele momento. Pode sim, ter se apresentado como a mais promissora ou, simplesmente, a melhor conhecida, sempre tendo em vista as redes sociais construídas pelos emigrantes nas duas pontas do oceano. Nesse sentido, o impulso ao êxodo, em muitos casos, foi mais uma situação privada de melhoramento do que a coação de uma realidade sem uma via de saída. ${ }^{32}$

E ainda, o fato dos moradores estarem ligados a parentes e vizinhos por vínculos pessoais fortes, porque estreitos e solidários, quando um indivíduo da aldeia emigrava, notícias passavam a ser divulgadas sobre possibilidades de emprego, e os primeiros que emigraram acabaram por 
abrir estradas que passaram a ser seguidas por amigos e parentes. Assim, redes sociais e cadeias migratórias organizadas e mantidas em ambos os lados do Atlântico divulgavam oportunidades de trabalho aos futuros imigrantes, apontando destinos, viabilizando as viagens, bem como garantindo a recepção e os meios de sobrevivência nos primeiros tempos na nova terra. ${ }^{33}$

Considerando os registros dos deslocamentos dos aldeões de Oneta durante o Oitocentos, uma característica que logo chama a atenção é o predomínio dos homens nesse processo. Isso pode ser explicado, até certo ponto, pelo próprio modelo migratório das áreas montanhosas, no qual estava implícito o trabalho das mulheres na agricultura, durante o período que os homens permaneciam fora da aldeia. Uma outra característica é que eram fluxos emigratórios de trabalho sazonal, que muitas vezes envolviam vários membros de uma mesma família, sendo que, entre os deslocamentos masculinos, o predomínio foi de escultores em gesso e, entre as mulheres, a ocupação como doméstica.

A partir da primeira metade do referido século a aldeia vivenciou um crescimento das migraçóes masculinas, sendo que a grande maioria das mulheres permaneceu no povoado. Alguns dados quantitativos fornecem uma dimensão dessa realidade. Em 1850, quando a população da aldeia era composta por 315 habitantes, que conformavam 61 núcleos familiares, cinco deles (8\%) eram chefiados por mulheres. Em 1870, em uma população de 300 habitantes, que constituíam 56 grupos familiais, 12 deles (21\%) estavam sob a responsabilidade das mulheres. Em 1884, quando a população de Oneta era de 285 habitantes, que formavam 65 núcleos, 21 destes (32\%) estavam confiados às mulheres. ${ }^{34}$ Percentuais elevados se considerarmos que entre o período final do século XIX e início do XX, 9\% das famílias italianas possuíam seus chefes emigrados; e em regiōes ao Sul, esses deslocamentos masculinos chegaram a $22 \%{ }^{35}$

Analisando estes números, é possível perceber que a partir de 1870 o índice de lares chefiados por mulheres quadruplicou em relação às décadas anteriores e, daí em diante, manteve-se sempre bastante elevado. Tal crescimento, provavelmente, esteve relacionado à intensificação dos deslocamentos transoceânicos então em curso.

Agora, se cruzarmos as ponderaçôes acima - a maior mobilidade masculina e o predomínio dos escultores - é plausível pensar que um dos motivos para a reduzida participação feminina nos deslocamentos, pode ter sido a falta de canais de informação capazes de colocar as mulheres 
em contato com as oportunidades existentes, e não a inexistência de oportunidades de trabalho realmente. Foi Franco Ramella quem sinalizou nessa direção, ao colocar que essa variável poderia influenciar nas escolhas e até mesmo influenciar as famílias, empurrando ou retendo a movimentação das mulheres nas migrações periódicas. ${ }^{36}$ Segundo o autor, certamente não faltavam oportunidades de trabalho nas localidades e países para os quais os emigrantes italianos se dirigiam, nas quais as mulheres pudessem se empregar. Provavelmente, não havia era conexão entre a área de partida e a de recepção dos emigrantes e, conseqüentemente, não circulavam notícias sobre possibilidades de trabalho para as mulheres no exterior.

A conseqüência imediata desse modelo migratório que privilegiou os deslocamentos dos componentes masculinos, foi o deslocamento da função de chefe de família da pessoa dos homens para a das mulheres que, por conseguinte, desencadeou mudanças na vida dos indivíduos, de suas famílias e da própria comunidade. Uma modificação tão significativa que atualmente se constitui em um ponto de referência frequentemente evocado pelos moradores da aldeia, durante o trabalho de construção e atualização da memória da experiência emigratória. É nesse sentido que podemos compreender o relato da depoente Maria Grazia Micheli, cujos parentes foram imigrantes no Brasil e nos Estados Unidos, quando narrou que com as partidas dos homens, Oneta transformava-se em uma

aldeia cheia de donas das casas, de mulheres mandonas. Elas que faziam tudo: deviam fazer as coisas, mandar adiante a família, mandar adiante os campos, cuidar e educar os filhos. Não era só a minha avó não. Havia um grande número de mulheres que tinham os maridos emigrados. Tantas! ${ }^{37}$

Dessa maneira, era chegada a temporada das mulheres. Uma estação que trazia uma carga muito grande de trabalho para todas as mulheres da aldeia, como também para tantas outras que habitavam as áreas montanhosas dos Apeninos toscanos. Conforme observou Adriana Dadà, com o afastamento dos homens as mulheres viam aumentar as tarefas da casa e fora dela, principalmente se o núcleo familiar possuísse o seu próprio pedaço de terra. A maior parte dos trabalhos agrícolas, dos cuidados com os animais, da colheita dos produtos do bosque ficava ao encargo das mulheres, mesmo quando os homens retornavam para executar os trabalhos mais pesados, como a aragem dos terrenos, o corte do feno e de grãos, e a colheita de castanhas. ${ }^{38} \mathrm{E}$ muitas mulheres solicitavam aos seus maridos que retornassem ao menos em maio-junho [entre a primavera e o verão] 
para "dar uma mão", pois esse era o momento dos trabalhos mais pesados. ${ }^{39}$ Dadà ressaltou ainda, que nessa região era comum uma mulher ser chamadas de "bersagliera", pois em italiano bersagliere designa o soldado militar. Algo como "mulheres-homens", uma alusão ao sentido real do termo, isto é, à pesada carga de trabalho que caberia aos homens suportar; mas que, provavelmente, o significado do vocábulo também estivesse relacionado aos encargos e a responsabilidade da função.

Nesse mesmo sentido, Paola Corti observou que nas primeiras ondas migratórias de grande parte da Península, realmante ocorreu uma feminização de muitas áreas de partidas, na qual as mulheres possuíam freqüentemente um papel exclusivo. Elas constituíram, de fato, o ponto de apoio e de estabilidade econômica, psicológica e social das famílias, diante da instabilidade do empreendimento migratório, onde eram precárias as atividades e profissões desenvolvidas pelos homens em outros países. ${ }^{40}$ Era a agricultura na qual eram empregadas as mulheres, que garantia uma parte da subsistência das famílias, quando os seus componentes masculinos se encontrassem no exterior. ${ }^{41}$

Em pleno desempenho de seus papéis de donas da casa, as mulheres tomavam todas as decisões na ausência dos maridos, o que lhes concedia muita autonomia e liberdade de ação, bem como a possibilidade de poderem agir na primeira pessoa e serem as "donas de seus próprios narizes". Entretanto, por mais que as mulheres cumprissem com todas as suas obrigações e incumbências na família e os aldeões estivessem habituados com as idas e vindas de muitos de seus moradores, nada disso as isentava de serem vistas com olhos vigilantes e críticos, e de estarem sujeitas às duras condenaçôes morais pelos outros membros da comunidade.

Interessante foi perceber que se na ausência dos maridos as famílias eram estruturadas sobre outras bases, pois eram mulheres quem cuidavam da administração doméstica e dos filhos, da produção agrícola e se responsabilizavam pela manutenção do grupo; com o retorno dos maridos a Oneta, a casa seguia o seu curso, ou seja, as mulheres continuavam como "donas da casa”. É Maria Grazia Micheli quem relembra:

$\mathrm{Eu}$, por aquilo que me recordo, que me contaram e também contou a minha mãe, quando o meu avô retornava dos Estados Unidos, não se alterava muito a vida da casa. Meu avô vinha, ficava seis meses ou um ano e depois partia novamente.

A minha avó Giustina continuava a cultivar os campos que tinha e, naturalmente, o meu avô a ajudava. Porém, era ela a dona $d a$ casa. ${ }^{42}$ 
Mesmo quando o meu avô estava aqui, quando voltava, continuava a ser ela a dona da casa.

Era ela quem dirigia tudo. Se tivesse necessidade de chamar uma pessoa para fazer um trabalho, era ela quem se preocupava. ${ }^{43}$

Recordando que as emigrações de Oneta envolveram predominantemente os membros masculinos dos grupos familiares, e que entre estes estavam aqueles que desempenhavam a função de chefes de família; então, além de Giustina, outras mulheres igualmente tornavamse as responsáveis por suas famílias. Umas temporariamente, outras por toda a vida, pois acontecia de maridos emigrarem e não mais retornarem, pois não foram poucos aqueles que morreram na "América".

\section{As mulheres, a grande emigração e a História}

Após o reencontro com uma Oneta que há mais de um século presenciou a partida de alguns de seus habitantes para terras brasileiras, ao menos duas ponderações merecem ser feitas.

A primeira delas relaciona-se a um ato de perversão empreendido e construído historicamente pelas sociedades ocidentais, ao delimitar as fronteiras entre dois mundos: o masculino e o feminino. Assim, espaços, atividades, cultura, mentalidade, comportamentos, trabalho, enfim, todas as manifestações e as relações humanas passaram a ser enquadradas na moldura de um mundo ou de outro. Nesse sentido, é possível afirmar que em Oneta as mulheres tenderam a desenvolver atividades que ficaram circunscritas ao território ocupado pela aldeia e em áreas circunvizinhas; enquanto os homens passaram a exercer profissões fora dos muros do povoado. Não é demais pensar que existiu uma delimitação de espaços para os dois sexos: aquele interno, situado dentro dos muros da aldeia, o aquém-fronteiras, que foi preferencialmente feminino; já o exterior, o além-fronteiras, constituiu-se prioritariamente como masculino. ${ }^{44}$ Dois mundos foram construídos: um mundo feminino mais fechado, ligado às atividades agrícolas, aos trabalhos mais humildes e pesados, em oposição a um mundo masculino móvel, aberto a outras culturas e experiências. ${ }^{45}$

Sendo assim, é possível conjecturar que as atividades ligadas ao cultivo da terra eram consideradas, pelos aldeões, como mais duras e de menor rendimento. O que nos leva a pensar que, além da existência de uma delimitação de espaços para os dois gêneros, havia valoraçôes distintas para as atividades produtivas: aquelas relacionadas às atividades agrícolas eram freqüentemente consideradas secundárias e, por esta razão, menos 
valorizadas, ficando sob a responsabilidade das mulheres; já aquelas artesanais, fabris ou comerciais que podiam ser desenvolvidas em outras localidades ou regiōes, que não as aldeias onde os indivíduos residiam, possuíam um status mais elevado, sendo mais valorizadas e cabendo aos homens. E isto por uma razão simples: o calendário das migrações não respeitava os tempos do trabalho rural, sobretudo no caso dos vendedores ambulantes e dos trabalhadores da construção civil. ${ }^{46}$

De acordo com tais ponderações, claro está que o referido modelo migratório foi construído em base sexocentrista, marcado pela dominação masculina, seja por ter privilegiado os deslocamentos dos homens, seja por ter reafirmado os espaços destinados às mulheres, isto é, a casa, a família, o mundo doméstico e o cultivo da terra. ${ }^{47}$

A segunda ponderação que deve ser feita é o reconhecimento da existência de distorções e silêncios produzidos pelas sociedades ocidentais, quando o tema é a participação feminina nos processos produtivos e sociais. Como foi possível perceber, seja no contexto do próprio povoado, das regiōes circunvizinhas a ele ou da Península Itálica, durante os grandes fluxos populacionais de massa as mulheres foram personagens ativas no interior de suas famílias e do processo migratório. Sendo assim, não há dúvida que a migração feminina possuiu um peso qualitativo e determinante. ${ }^{48} \mathrm{O}$ que significa dizer que é problemática a não inscrição das mulheres em um "fazer" histórico mais tradicional, que ao tratar das grandes migrações transnacionais desconsidera as mulheres.

Finalmente, vale salientar e reconhecer que fossem as mulheres solteiras, casadas ou viúvas, mães ou filhas, camponesas, donas de casa ou artesãs, elas tomaram suas decisões, fizeram suas escolhas e participaram ativamente dos grandes deslocamentos populacionais que uniram a Itália ao Brasil a partir de fins do Oitocentos.

\section{Notas e Referências}

* Este artigo é uma adaptação de um capítulo de minha tese de doutorado, intitulada Entre histórias, fotografias e objetos: imigração italiana e memórias de mulheres, defendida no Programa de Pós-Graduação em História da Universidade Federal Fluminense (Brasil), em 2008, sob a orientação da Profa Angela de Castro Gomes e do Prof. Angelo Trento, da Università degli Studi di Napole L'Orientale.

1 Segundo Pollak, os guardiōes ou mediadores da memória são indivíduos que, no interior das organizações e instituições de que são membros - como clubes, 
associações, sindicatos, partidos ou famílias - dedicam-se à guarda e à reelaboração permanente da memória de seu grupo, produzindo discursos organizados e controlados, referenciados ao passado, que permitem a coesão do grupo, a conservação da identidade. Os mediadores são os narradores privilegiados da história do grupo, os depositários de histórias vividas por seus membros, bem como os colecionadores de bens materiais de extremo valor simbólico para o grupo que, ao serem expostos, permitem a atualização de sua memória. Nas famílias esse papel é geralmente exercido pelas mulheres, na condição de avós. Michael POLLAK. "Memória, esquecimento, silêncio". Estudos Históricos. Rio de Janeiro: CPDOC-FGV, vol. 2, n. 3, pp. 3-15, 1989; Myriam Moraes Lins de BARROS. "Memória e Família”. Estudos Históricos, Rio de Janeiro: CPDOCFGV, v. 2, n. 3, pp. 29-41, 1989.

2 Desenvolvi a noção de caixinha de lembranças a partir do conceito de lugar de memória de Pierre Nora. Segundo o autor, os lugares de memória são referências materiais, simbólicas e funcionais, com as quais indivíduos e grupos se identificam, e em torno dos quais se agregam, o que lhes garante o sentimento de pertencimento. Os lugares de memória podem ser tanto grandes rituais e momentos, como comemorações e álbuns de retratos, que materializam sinais de pertença de grupo ou de um indivíduo a uma sociedade. Pierre NORA. "Entre memória e história: a problemática dos lugares”. Proj. História. São Paulo: n. 10, pp. 7-28, 1993.

3 Além de Célia CONSANI e Laís CONSANI, as demais depoentes orais brasileiras foram: Emília Bonanni de ALMEIDA; Angela Conti BONANNI; Maria José Silva GUEDES; Elba Consani MARINS; Vilma Marins CAMPOS; Moema Cruz PERRONE e Maria Julia Pelegrini SILVA.

4 Michael POLLAK e Myriam Moraes Lins de BARROS, op. cit.

5 Oneta pertence administrativamente ao município de Borgo a Mozzano, situado na província de Lucca (no Médio Vale do Rio Serchio), na região da Toscana.

6 Depoentes orais italianos: Antonio MICHELI, Ferruccio SILVESTRI, Licia SILVESTRI, Luciano GIGLI, Maria Albina PELLEGRINI, Maria Grazia GIGLI, Maria Grazia MICHELI, Maria Luisa UGOLINE, Maria PONZI, Maurizio MICHELI, Piero MICHELI e Vincenzo MICHELI. Minha permanência na aldeia foi possível em função de uma bolsa-sanduíche de doutorado concedida pela Coordenação de Aperfeiçoamento de Pessoal de Nível Superior-CAPES.

7 Paola CORTI, P.”Donne che vanno, donne che restano. Emigrazione e comportamenti femminili”. Annali Cervi, 12, pp. 213-235, 1990; L. PASSERINI. "Storia delle donne, storia di genere: contributi di método e problemi aperti”. Annali Cervi, 12, pp. 9-22, 1990; Adriana DADÀ. La Merica. Bagnone, Toscana - Califórnia, USA. Firenze: Morgana, 2006. 
8 Luisa PASSERINI. "Storia delle donne, storia di genere: contributi di método e problemi aperti”. Annali Cervi, 12, 1990, pp.13-14,. Os termos fontes deformadas e carentes utilizados pela autora foram elaborados por Amalia Signorelli e Emilio Franzina, respectivamente.

9 Sobre a construção do feminino e do masculino na sociedade ocidental, bem como a elaboração e aplicação da categoria gênero, ou melhor, gêneros, cf.: P.BOURDIEU. A dominação masculina. Rio de Janeiro: Bertrand Brasil, 1999; Michelle PERROT. "Práticas da Memória Feminina”. Revista Brasileira de História. n. 18, ago./set. 1989; S. G. COSTA. "Gênero e História”. In: Martha ABREU; Rachel SOIHET (Org.) Ensino de história: conceitos, temáticas e metodologia. Rio de Janeiro: Casa da Palavra, 2003. pp. 187-208; Joan SCOTT. "Gênero: uma categoria útil para a análise histórica". SOS Corpo: gênero e cidadania, 1995.

10 Francesco Maria PELLEGRINI. Borgo a Mozzano e Pescaglia nella storia e nell'arte. Lucca: Maria Pacini Fazzi Editore, 1987, p. 302.

11 Popolazione per frazione. Anagrafe della popolazione residente di Borgo a Mozzano, Borgo a Mozzano, anno 2006. De agora em diante APR, a. 2006.

12 Note reclutamento. Parrocchia di Santo Ilario, Oneta, anni 1819-1824. De agora em diante PSI, a.1819-1824.

13 Nesse período a empregada doméstica e a arrumadeira recebiam a denominação de serva (e); e o menino ajudante, o jovem-aprendiz, chamava-se garzone e, neste caso, é difícil saber o ofício que verdadeiramente exerceu, porque ser garzone já se configurava em uma profissão.

14 Tais regras foram igualmente e anteriormente observadas por Fortunata PISELLI (1981) em seu estudo sobre as relações de parentela em uma comunidade do Cosentino, na Calábria. Fortunata PISELLI. Parentela e Emigrazione. Mutamenti e continuità in una comunità calabrese. Torino: Giulio Einaudi Editore. 1981. 15 id. ibid, p. 391.

16 Maria Luisa UGOLINE; Maria Albina PELLEGRINI. Depoimento, Oneta, 25 out. 2006. LABHOI, UFF, Fita 4, lado B.

17 Laís Consani SCARPA. Depoimento, Niterói, 20 out. 2001. LABHOI, UFF, Fita 1, lado A.

18 Adriana DADÀ. "Emigrazione e storiografia: primi risultati di una ricerca sulla Toscana”. Italia contemporanea, n. 192, pp. 487-502, set. 1993, p. 495.

19 Maria Grazia MICHELI. Depoimento, Oneta, 16 out. 2006. LABHOI, UFF, Fita 1, lado A.

20 Adriana DADÀ. L'emigrazione in Toscana: il ruolo di donne e bambini. Montefegatesi: Ed. FILEF, 1994, pp. 7-9.

21 São massas como as nossas panquecas, só que feitas com fubá de milho, água e sal. 
Maria Grazia MICHELI. Depoimento, Oneta, 16 out. 2006. LABHOI, UFF, Fita 1, lado A. As neccie são também como panquecas, mas feitas com farinha de castanhas; e a polenta de neccio é a polenta de farinha de castanhas. Hoje as neccie são servidas recheadas com queijos, geléias e frios, mas durante o Oitocentos e início do Novecentos, as pessoas alimentavam-se somente da massa.

Attilio ZUCCAGNI-ORLANDINI. Ricerche Statistiche sul Granducato di Toscana. Firenze: Ministero delle Finanze, 1848, p. 409)

24 Roberto FERRETTI apud Adriana DADÀ, 'Uomini e strade dell'emigrazione dall'Appennino Toscano”. In: D. ALBERA; P.CORTI, (a cura di). La montagna mediterranea: una fabbrica d'uomini? Mobilità e migrazioni in una prospectiva comparata (secoli XV-XX). Torino: Gribaudo,Cavallermaggiore, 2000, p. 154. Registro dei Matrimoni, PSI, $\mathrm{n}^{\circ}$ 4, 8-2-1853 - 25-7-1858; Registri dei Morti, PSI, 21-4-1857 - 4-1-1866. Os figuriai ou escultores em gesso, com suas estatuetas deslocaram-se por diversos países da Europa, da América do Norte e América dos Sul. Provavelmente, eram eles que enviavam e divulgavam notícias sobre oportunidades de trabalho existentes em outras terras. Essa profissão era originária dessa região da província de Lucca, ou seja, o Vale do Rio Serchio. Adirana DADÀ. "Emigrazione e storiografia: primi ...”, op. cit., p. 495.

Adriana DADÀ, “Uomini e strade dell'emigrazione ...”, op. cit., p. 153.

Adriana DADÀ. L'emigrazione in Toscana: ..., op. cit., p. 8.

29 Franco RAMELLA. "Reti sociali, famiglie e strategie migratorie". In: Piero BEVILACQUA; Andreina DE CLEMENTI; Emilio FRANZINA (a cura di). Storia dell'emigrazione italiana: partenze. Roma: Donzelli Editore, 2001, p. 146.

30 Statistiche dell'emigrazione all'estero, ARCHIVIO COMUNALE DI BORGO A MOZZANO, Borgo a Mozzano, cat. IV, sez 3, a. 1878-1903, faltando os dados para 1880 e 1881 . Todas as informações sobre Borgo a Mozzano aqui consideradas foram elaboradas por Lucilla BRIGANTI.

31 Franco RAMELLA, Reti sociali, famiglie e ..., op. cit., p. 146.

32 Antonio GIBELLI. "Andar per funghi, trovare l'America. Il senso di una ricerca". In: La vie delle Americhe. L'emigrazione tra evento e raconto. Genova: SAGEP EDITRICE, 1989, pp.10-11; Andreina DE CLEMENTI, A. "L'emigrazione transoceanica del Mezzogiorno continentale. Cause e effetti”. In: Marcello SAIJA, (a cura di) L'emigrazione italiana transoceanica tra Otto e Novecento e la storia delle comunità derivate. Atti del Covegno Internazionale di Studi. Salina, 1-6 giugno 1999. vol. I-II. Messina, Edizione TRISFORM, 2003, p.69.

33 A noção de redes sociais aqui utilizada foi desenvolvida por Franco RAMELLA. Cf.: Franco RAMELLA. "Movilidad geográfica y movilidad social. Notas sobre la emigración rural de la Itália del Noroeste (1880-1914)". Estudios Migratórios Latinoamericanos, 6, 17, 1991, pp. 107-118; . "Por un uso fuerte del 
concepto de red en los estudios migratórios”. In. María BJERG.; Hernán OTERO. (Comp.). Inmigracion y redes sociales en la Argentina Moderna. Tandil: CEMLA - IEHS, 1995. pp. 9-21; . "Reti sociali, famiglie e strategie migratorie". In: Piero BEVILACQUA; Andreina DE CLEMENTI; Emilio FRANZINA (a cura di). Storia dell'emigrazione italiana: partenze. Roma: Donzelli Editore, 2001. pp. 143-160; "Gli studi sull'emigrazione tra vecchi paradigmi e nuove prospettive". In: Marcello SAIJA. (a cura di) L'emigrazione italiana transoceanica tra Otto e Novecento e la storia delle comunità derivate. Atti del Covegno Internazionale di Studi. Salina 1-6 giugno 1999. v. I-II. Messina: Edizione TRISFORM, 2003. pp. 25-34. Já o termo cadeias migratórias foi elaborado pelos irmãos MACDONALD, estudiosos das migrações em direção à Austrália. Ver: John Stuart MACDONALD; Leatrice MACDONALD. Chain Migration, Ethnic Neighborhood and Social Networks, The Milbank Memorial Fund Quaterly, (XLII), 1, enero. pp. 82-86. Nota dell'Anime della Parrocchia di Oneta, PSI, a. 1818-1884. Dino CINEL apud Paola CORTI. "Donne che vanno, donne che restano. Emigrazione e comportamenti femminili”. Annali Cervi, 12, 1990, p. 217. Franco Ramella, op. cit.,2001, p. 147.

Maria Grazia MICHELI. Depoimento, Oneta, 16 out. 2006. LABHOI, UFF Fita 1, lado A. Vale informar que dona da casa é a tradução que mais se aproxima de "padrona", no sentido que a depoente imprimiu à palavra, ou seja, de uma mulher mandona, que dirigia a casa e exercia a autoridade máxima no núcleo familiar.

38 Adriana DADÀ, op. cit., 2000, p. 161.

39 Mario ARPEA apud Adriana DADÀ, Uomini e strade dell'emigrazione ..., op. cit., p. 161.

$40 \quad$ Paola CORTI, op. cit., 1990, p. 218.

41 Franco RAMELLA, op. cit., 2001, p. 151.

42 Dona $d a$ casa é a tradução que mais se aproxima de padrona, no sentido que a depoente imprimiu à palavra, ou seja, de uma mulher mandona, que dirigia a casa e exercia a autoridade máxima no núcleo familiar.

43 Maria Grazia MICHELI. Depoimento, Oneta, 16 out. 2006. LABHOI, UFF Fita 1, lado A.

44 A análise sobre o binarismo masculino/feminino enquanto regra organizadora da sociedade encontra-se em Pierre BOURDIEU. A dominação masculina. Rio de Janeiro: Bertrand Brasil, 1999. Nesse trabalho o autor realiza um estudo etnológico sobre a sociedade cabila, o autor constatou que as diferenças sexuais regiam a divisão do trabalho entre os membros da comunidade, mas elas eram também perceptíveis no conjunto de oposiçôes que organizavam todo o cosmos, 
dividindo todas as coisas e atividades segundo a oposição entre o masculino e o feminino, um sistema de oposições homólogas: alto/baixo, reto/curvo, seco/ úmido, direito/esquerdo, quente/frio.

45 Bruna BIANCHI. "Lavoro ed emigrazione femminile (1890-1915)”. In: Piero BEVILACQUA; Andreina DE CLEMENTI; Emilio FRANZINA (a cura di). Storia dell'emigrazione italiana: partenze. Roma: Donzelli Editore, 2001. p. 259.

46 Dionigi ALBERA; Paola CORTI. (a cura di). La montagna mediterranea: una fabbrica d'uomini? Mobilità e migrazioni in una prospectiva comparata (secoli XV-XX).Torino: Gribaudo,Cavallermaggiore, 2000, p. 16.

47 Segundo Pierre Bourdieu, a dominação masculina é uma forma particular e particularmente acabada da violência simbólica presente em nossa sociedade, que naturaliza a oposição entre os gêneros masculino e feminino, quando, na realidade, trata-se de uma construção social. Pierre BOURDIEU, op. cit., p. 17.

48 Paola CORTI, op. cit., p. 225. 